\title{
Arte Rupestre: uma experiência de ensino e pesquisa em Artes Visuais no PIBID
}

\author{
Denise Castanha de Avila de Lemos \\ (Artes Visuais - Licenciatura/Centro de Artes/UFPel) \\ denlemos@gmail.com \\ Maristani Polidori Zamperetti \\ (Centro de Artes, PPGE/FaE/UFPel) \\ maristaniz@hotmail.com
}

\section{RESUMO}

O texto busca apresentar experiências na docência em Artes Visuais desenvolvidas no âmbito do Programa Institucional de Bolsa de Iniciação a Docência - PIBID (2014 a 2016), onde foram realizadas oficinas de pintura e desenho sobre arte rupestre nas escolas atendidas pelo programa, e também em outras escolas da rede municipal e estadual da cidade de Pelotas. A arte rupestre é uma das primeiras formas de expressão artísticas humanas e buscamos promover, através de oficinas de arte, a construção do conhecimento através da manipulação, experimentação e criação de matérias da natureza, que permitem entender a história e a cultura de uma forma mais dinâmica e atrativa. Com estas atividades pretendemos desenvolver novas metodologias na área de ensino da arte, levando aos alunos o conhecimento sobre a história da arte pré-histórica.

Palavras-chave: Artes Visuais; História da Arte; Arte Rupestre; PIBID

\section{INTRODUÇÃO}

A partir da metodologia de projetos de trabalho por meio de oficinas, busquei promover uma forma de comunicação diferenciada entre docente e discente, onde todos os componentes do grupo fazem parte de uma única equipe de trabalho. Tal visão está apoiada na fala de Vieira e Volquind (2002, p. 17), quando afirmam que “[...] através da oficina, podemos ensinar de forma mais humanizada, onde a cultura e os valores dos alunos participantes são respeitados. As oficinas promovem a abertura de um espaço de aprendizagem alternativo”.

Proporcionar aos alunos as oficinas sobre a arte rupestre é possibilitar uma forma dinâmica de aprendizado, onde o aluno, durante a ação, pode refletir e entender as dificuldades que os povos da época encontravam para confeccionar suas pinturas, entendendo seus hábitos e costumes. As atividades de arte rupestre desenvolvidas por mim, enquanto integrante do PIBID - Artes Visuais da UFPel, sob coordenação da Profa. Maristani Zamperetti, foram aplicadas para públicos diferenciados, em escolas municipais e estaduais e outros eventos da cidade de Pelotas, RS, nos anos de 2015 e 2016.

\section{METODOLOGIA DE ENSINO - AS OFICINAS SOBRE ARTE RUPESTRE}


Há milhares de anos antigos povos buscavam produzir artisticamente, de forma organizada, imagens que persistem até hoje. A arte rupestre é uma das formas artísticas mais antigas, com seus registros nas paredes das cavernas.

Do francês rupestre, o termo designa gravação, traçado e pintura sobre suporte rochoso, qualquer que seja a técnica empregada. Considerada a expressão artística mais antiga da humanidade, a arte rupestre é realizada em cavernas, grutas ou ao ar livre. [...] Alguns especialistas criticam o uso do termo "arte" para fazer referência às inscrições sobre pedra que remontam, em geral, aos povos de épocas pré-históricas, na medida em que pinturas e gravuras descobertas pelas pesquisas arqueológicas nem sempre teriam, hoje, um sentido estético evidente. Apesar disso, convenciona-se chamar de "arte" essas expressões plásticas que fornecem acessos valiosos para o estudo de várias fases da história da humanidade (ITAÚ CULTURAL, 2017).

O território brasileiro é rico em testemunhos arqueológicos. O Brasil possui dezenove sítios inscritos na Lista do Patrimônio Mundial da UNESCO, sendo onze sítios do Patrimônio Cultural e sete sítios do Patrimônio Natural, onde registram importantes evidências da presença humana na história do nosso continente e país.

\begin{abstract}
São os sítios arqueológicos com vestígios dos caçadores que iniciaram a ocupação da América do Sul, os monumentais sambaquis do litoral, as inúmeras aldeias de grupos ceramistas dispersas por todo o país que contém informações sobre o passado do que é hoje o território brasileiro e a diversidade cultural que foi passo a passo aqui se instalando (GASPAR, 2006, p. 07).
\end{abstract}

Como bolsista do PIBID $^{1}$, me apoio na interdisciplinaridade como uma forma de desenvolver um trabalho de integração dos conteúdos de artes visuais com outras áreas de conhecimento, buscando contribuir para o aprendizado do aluno de maneira integral.

O PIBID/UFPel visa desenvolver atividades interdisciplinares para conhecer de forma mais aprofundada e integrada a escola, os alunos e professores e também os próprios bolsistas, inseridos naquele contexto. Desta forma, a interdisicplinaridade revela

[...] atitudes de reciprocidade que impele à troca, que impele ao diálogo - ao diálogo com pares idênticos, com pares anônimos ou consigo mesmo atitude de humildade diante da limitação do próprio saber, atitude de perplexidade ante a possibilidade de desvendar novos saberes, atitude de desafio - desafio perante o novo, desafio em redimensionar o velho - atitude de envolvimento e comprometimento com os projetos e com as pessoas neles envolvidas, atitudes, pois, de compromisso em construir sempre da melhor forma possível, atitude de responsabilidade, mas, sobretudo, de alegria, de revelação, de encontro, enfim, de vida (FAZENDA, 1994, p.82).

\footnotetext{
${ }^{1}$ O PIBID é uma iniciativa da Fundação Capes, do Ministério da Educação, que busca o aperfeiçoamento e a valorização da formação de professores para a educação básica. O programa concede bolsas a alunos de licenciatura participantes de projetos de iniciação à docência desenvolvidos por Instituições de Educação Superior (IES) em parceria com escolas de educação básica da rede pública de ensino. Os projetos devem promover a inserção dos estudantes no contexto das escolas públicas desde o início da sua formação acadêmica para que desenvolvam atividades didático-pedagógicas (CAPES, 2016).
} 
Assim, surgiu o interesse de realizar um projeto, que pudesse trabalhar vários saberes, utilizando materiais simples, que podem ser encontrados na natureza e que são de fácil acesso para os alunos. Tal trabalho tem o intuito de promover uma reflexão sobre a pintura rupestre, que foi feita pelos homens pré-históricos, mas que pode gerar ideias para se pensar a arte contemporânea.

Em geral, inicio o trabalho apresentando representações de animais, plantas, pessoas e sinais gráficos abstratos, mostrando imagens de livros de história da arte (Figura 1), uma vez que acredito ser muito importante o manuseio e o contado dos alunos com livros impressos. Nas aulas, também uso algumas imagens impressas em folhas A3, para melhor utilização no momento da execução do trabalho.

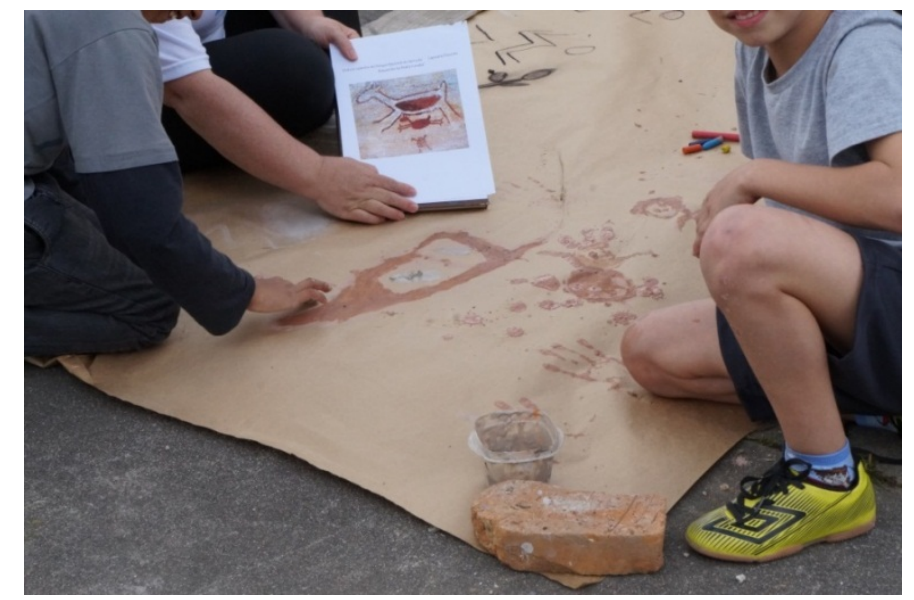

Figura 1: Manuseio de livro Fonte: acervo pessoal

Após, utilizo alguns metros de papel pardo posicionado no chão da sala ou no pátio da escola, e então convido os alunos para uma roda de conversa (Figura 2). Sugiro que se sentem no chão, em torno do papel, ficando livre a escolha do lugar. Alguns alunos, no início, se distanciam, mas conforme a atividade se desenvolve, eles se interessam e se unem ao grupo.

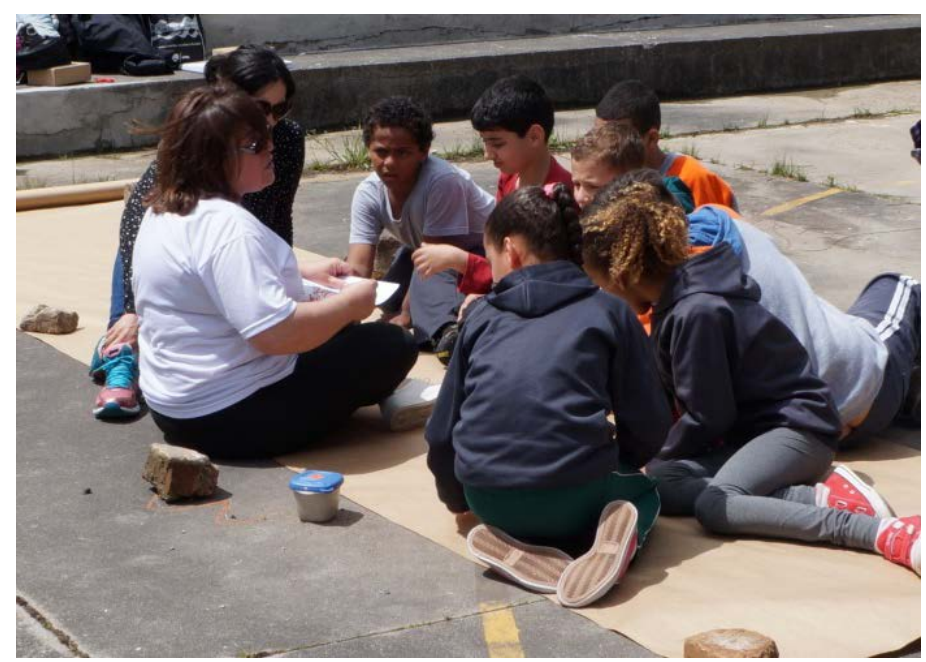

Figura 2: Roda de conversa com os alunos. Fonte: acervo pessoal 
Durante a conversa trago como primeiro assunto, os homens pré-históricos, que realizavam desenhos e pinturas nas paredes das cavernas retratando o cotidiano de caçadas, rituais e vida social. A arte rupestre nos permite uma leitura da vida de nossos antepassados. Da mesma forma, ao transitar por ruas de nossa cidade e vermos os grafites, é possível por meio destes, conhecer um pouco da vida cotidiana das pessoas que habitam estes contextos, a partir desta manifestação artística em espaços públicos. O grafite é um tipo de inscrição, desenho ou pintura feita em paredes. São imagens que remetem a sentimentos e ideais que invadem o nosso cotidiano.

\begin{abstract}
Atualmente no espaço urbano, grupos de jovens grafitam suas marcas e quadrilhas de traficantes assinalam sua presença em muros e prédios. São sinalizações que transmitem mensagens pertinentes ao grupo que as realizou e a seus contemporâneos. O hábito de perpetuar mensagens em pedra e paredões tem longa duração e diferentes significados (GASPAR, 2006, p. $08)$.
\end{abstract}

Logo após, trago o registro de imagens do cotidiano através da selfie (Figura 3). O termo em inglês é uma abreviação da expressão self-portrait photograph, que em português significa autorretrato fotográfico. A selfie é uma técnica que vem sendo usado principalmente por jovens, que com seus smartphones, capturam fotos de si mesmos em diferentes lugares e de diferentes formas, além de registros digitais por meio de fotografias que registram cena do cotidiano (ITAÚ CULTURAL, 2016).

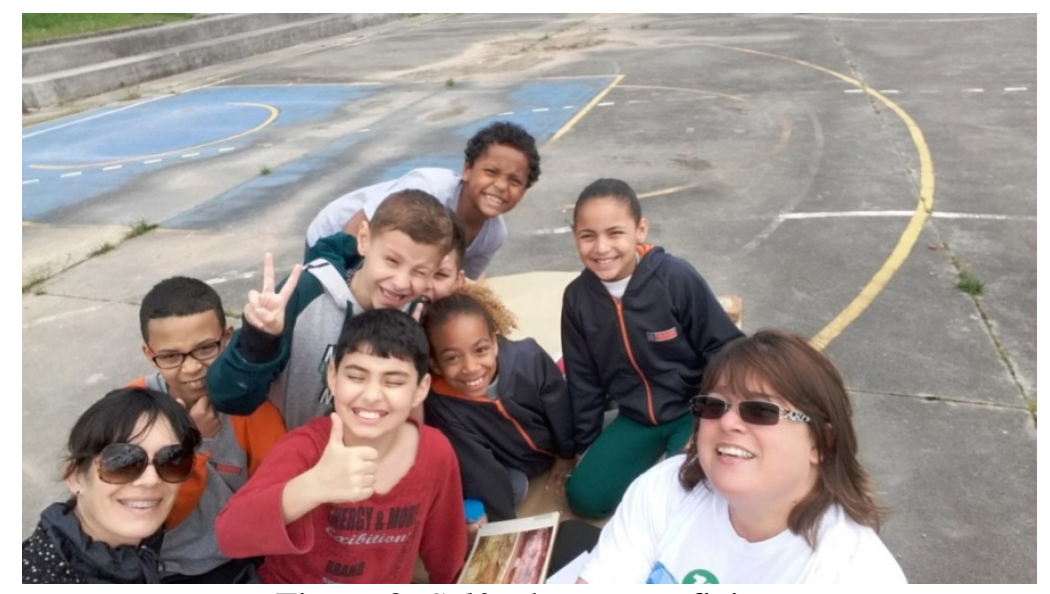

Figura 3: Selfie durante a oficina.

Fonte: acervo pessoal

Os assuntos da atualidade despertam o interesse dos envolvidos, e permitem estabelecer relações com cenas de pintura rupestre. Essa parte acontece com perguntas relacionadas sobre como eram os registros do cotidiano dos "homens das cavernas", tais como: onde foram feitos estes registros?; qual o material usado?; porque resistiu tantos anos?; como conseguiram esta pigmentação?; como foi feita a tinta?, dentre outros questionamentos. A partir destas reflexões cada aluno pode se expressar e criar sua cena (Figura 4). 


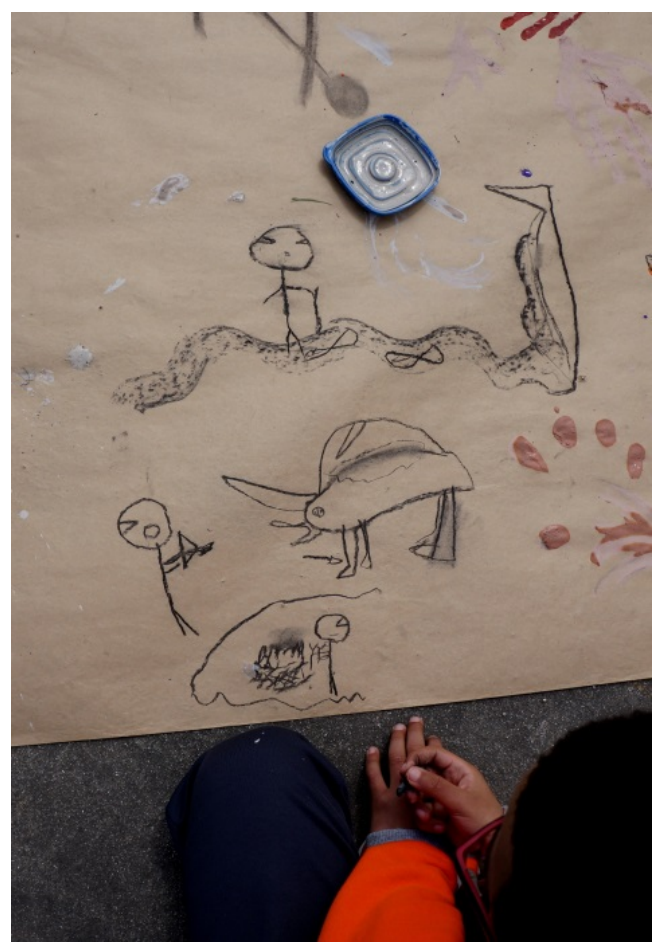

Figura 4: Desenho feito por aluno na oficina Fonte: acervo pessoal

No segundo momento apresento materiais como, argila, carvão, frutas de coloração forte, legumes, cascas de árvores, e sugiro a eles criarem pigmentos que serão usados no papel pardo, simulando uma parede de caverna. Quando a escola disponibiliza horário de três horas/aula, construímos as tintas com os alunos, usando terra, argila de coloração diferente, açafrão e café (que possibilita criarmos as tintas) (Figura 5).
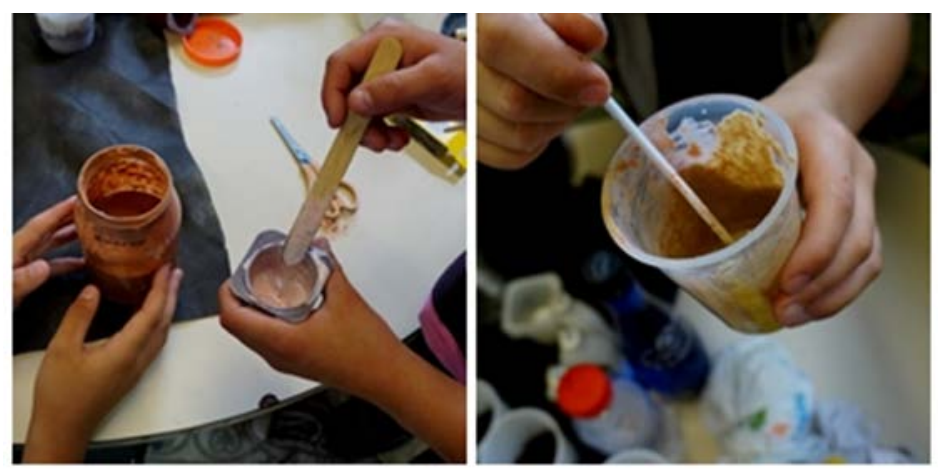

Figura 5: Criação de tintas a partir de colorações naturais Fonte: acervo pessoal

Alguns alunos dizem não saber desenhar, então retorno aos livros mostrando como os registros eram simples, porém expressivos. Em todas as oficinas tive participação efetiva, e ao final da cada uma delas os alunos se surpreendem com o trabalho pronto, elogiando e admirarando o trabalho.

Escolhi trabalhar com material compartilhado criando assim um ambiente solidário, onde cada um respeita o espaço e o tempo do outro. Cada oficina tem sua 
particularidade e vai fluindo de acordo com a vivência dos alunos, uma vez que as reações são diferentes perante o material.

\section{AS ATIVIDADES NO ÂMBITO DO PIBID - ARTES VISUAIS}

A primeira oficina ocorreu na escola Dom Joaquim Ferreira de Mello, escola onde atuo como bolsista do PIBID. Nesta instituição trabalhei com a turma de $6^{\circ}$ ano. Os alunos participaram com muito interesse, compartilharam o material e se mostraram solidários com os colegas. Ao final os próprios alunos fizeram questão de expor o material na parede da sala (Figura 6 e 7).

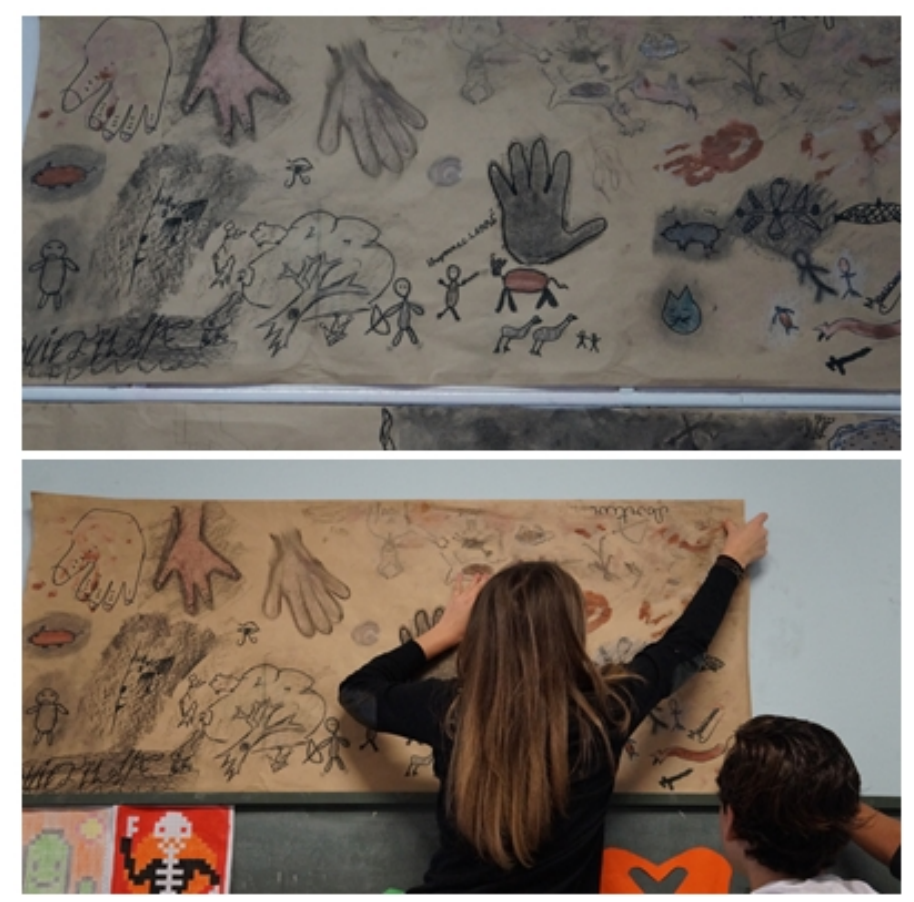

Figura 6 e 7: Painel com desenhos da turma do $6^{\circ}$ ano e exposição na parede da sala.

Fonte: acervo pessoal

A segunda oficina foi realizada no Colégio Municipal Pelotense, a partir de um convite do Projeto Arte na Escola do Centro de Artes, UFPel ${ }^{2}$. A atividade nesta escola foi aplicada junto com colegas bolsistas do PIBID e com bolsistas do projeto Arte Escola. A tarde foi marcada pelo circuito de artes e brincadeiras alusivo ao Dia das Crianças. Participaram cinco turmas, sendo duas dos $4^{\circ}$ anos, duas dos $3^{\circ}$ anos e uma do $5^{\circ}$ ano. A atividade foi realizada no pátio da escola e organizada no formato de circuito, de forma que os alunos participassem de todas as atividades propostas (Figura 8 e 9).

\footnotetext{
${ }^{2}$ Desde 1995 o Centro de Artes/UFPEL abriga O Projeto Arte na Escola, a partir de um convênio feito entre a UFPel e o Instituto Arte na Escola. O Instituto Arte na Escola resulta da institucionalização do Projeto Arte na Escola, criado em 1989 pela Fundação Iochpe. Tem como missão incentivar o ensino da Arte por meio de formação contínua do professor do ensino básico, investigando e qualificando processos de aprendizagem. Informações disponíveis em: http://wp.ufpel.edu.br/artenaescola/o-projeto-arte-naescola/ Acesso em: 02 mar. 2017.
} 


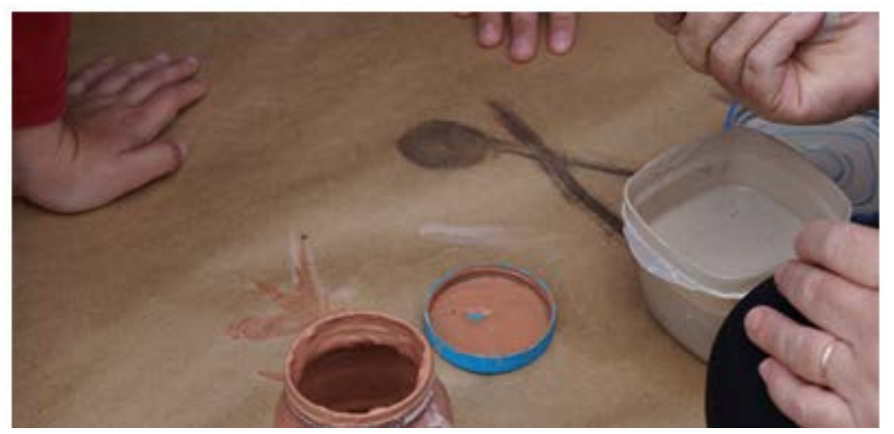

Figura 8: Elaborando tinta de argila com alunos do $5^{\circ}$ ano.

Fonte: acervo pessoal

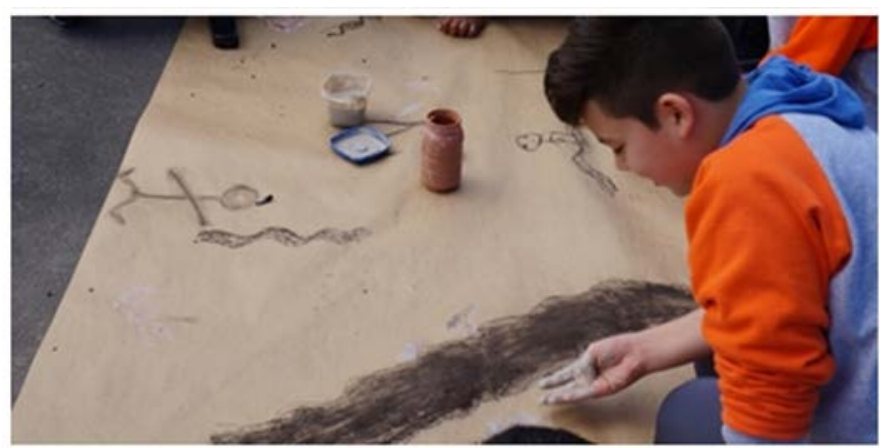

Figura 9: Aluno experimentando o carvão.

Fonte: acervo pessoal

As atividades realizadas nas escolas permitem que a formação dos futuros professores seja em contato com a realidade que encontrarão posteriormente. Sobre a experiência realizada no Colégio Municipal Pelotense, uma colega bolsista do PIBID Artes Visuais que acompanhou o trabalho relatou que:

[...] Um aluno me chamou e disse: professora quero mostrar umas coisas! Para minha surpresa e alegria era uma pasta recheada de desenhos lindos de grafites, pois queria ser grafiteiro. Nossa... eu levantei um desenho com um imenso sorriso e falei para minha colega nem tudo está perdido, ganhei meu dia! (BOLSISTA Z., RELATÓRIO, 2016).

Entendemos, desta maneira, que a formação do professor necessita ser sensível e reflexiva a partir de uma base sólida de conhecimentos específicos. Assim, além do domínio das materialidades, técnicas e fazeres do profissional-professor, ele precisa estar aberto ao que os alunos possuem, em termos de potencialidades, ou mesmo dificuldades. Pois, cada vez mais, a escola carece

[...] de um profissional que esteja aberto e qualificado para lidar com diferentes realidades e diversidade: cultural e educacional, situações de ensino , espaços e contextos, o que inclui o domínio de conhecimentos históricos, estéticos, artísticos, processuais, técnicos, de criação e processos de ensinar e aprender. Ele deve conhecer os materiais, os aspectos conceituais e filosóficos: da educação e da arte, mas sem se esquecer da complexidade e diversidade cultural que envolve todas as temáticas, práticas e contextos escolares (GOYA, 2015). 
Portanto, o trabalho realizado no PIBID - Artes Visuais por meio das oficinas sobre Arte Rupestre tem se mostrado rico em potencialidades, conjugando a história da arte e o fazer artístico, permitindo a fruição e o desenvolvimento do senso estético por meio da diversidade cultural e o conhecimento histórico.

\section{BREVES CONCLUSÕES}

As oficinas de arte possibilitam varias formas de expressão e comunicação, sendo um recurso pedagógico que me permitiu trabalhar de forma prática a história da arte antiga e contemporânea. Promovendo a ação, investigação e a reflexão sobre a arte rupestre, foi possível a abordagem teórica dos conhecimentos históricos sobre a arte a partir da interação pedagógica em dois contextos estudados.

Nestas atividades busquei abordar a arte rupestre, através de intervenções práticas, onde os participantes confeccionaram suas próprias tintas, tiveram contato com elementos da natureza e ao final, construíram um painel de pintura rupestre, colocado em exposição na escola. É satisfatório ver as crianças apropriando-se das diversas sensações produzidas pelos sentidos corporais, através das experimentações e manipulações realizadas no decorrer da oficina.

A valorização da pesquisa em sala de aula para o acadêmico promove a integração das diversas áreas do conhecimento em uma perspectiva interdisciplinar. Assim, a colaboração do Pibid - Artes Visuais para a parceria Escola-Universidade se mostra na conjugação dos diferentes contextos, proporcionando reverberações nos dois campos de atuação para os universitários e seus professorescoordenadores, como também para os professores supervisores e seus alunos (ZAMPERETTI, 2016).

\section{REFERÊNCIAS BIBLIOGRÁFICAS}

CAPES. Ministério da Educação. PIBID - Programa Institucional de Bolsa de Iniciação à Docência. Disponível em: <http://www.capes.gov.br/educacaobasica/capespibid/pibid> Acesso em: 19 out. 2016.

GASPAR, Madu. A arte rupestre no Brasil. Rio de Janeiro: Jorge Zahar editor, 2006.

GOYA, Edna de Jesus. O Pibid - A formação do professor de Artes Visuais e as atividades de ensino e pesquisa nas escolas municipais de Goiânia - segunda fase do Ensino Básico. In: II ENCONTRO INTERINSTITUCIONAL DO PIBID \& III ENCONTRO INSTITUCIONAL PIBID-UFRGS. [Anais do...] Porto Alegre, 01-02 mar, 2011, 08p. Disponível em: http://www.ufrgs.br/prograd/pibid/anais-doevento/salasdedebate/O\%20PIBID\%20\%20A\%20formacao\%20do\%20professor\%20de \%20artes\%20visuais\%20e\%20as\%20atividades\%20de\%20ensino\%20e\%20pesquisa\%2 0nas\%20escolas\%20municipais\%20de\%20goiania\%20\%20segunda\%20fase $\% 20 \mathrm{do} \% 20$ ensino\%20basico.pdf Acesso em: 22 nov. 2016.

FAZENDA, Ivani. Interdisciplinaridade, teoria e pesquisa. Campinas, SP. Papirus.1994. 
ITAÚ CULTURAL. A selfie na fotografia contemporânea. Disponível em: http://www.itaucultural.org.br/explore/blogs/blog-do-professor/a-selfie-na-fotografiacontemporanea/ Acesso em: 05 mar. 2016.

ITAÚ CULTURAL. Arte rupestre. Disponível em: http://enciclopedia.itaucultural.org.br/termo5354/arte-rupestre/ Acesso em: 24 fev. 2017.

VIEIRA, Elaine; VOLQUIND, Lea. Oficinas de ensino: o quê? Por quê? Como? Porto Alegre: EDIPURS, 2002.

ZAMPERETTI, Maristani Polidori. A formação docente inicial no PIBID - Artes Vi suais/UFPel - apontamentos experienciais. RELACult - Revista Latino-Americana de Estudos em Cultura e Sociedade, v.2, p.22-32, 2016. 